view them as natural resources over which they exercise absolute authority. Fair enough. But if only by virtue of their gyroscopic effect on global climate, forests impinge on the future of the global community. This worldwide interest offers abundant scope for conflict among nations. It also supplies an admirable challenge for nations to cooperate in providing funds and technical know-how to assist forest-owning nations to secure the future of what are, in some senses at least, everybody's forests.

This political tangle is the intrinsic agenda for the proposed commission, together with a host of scientific and technical questions. The task is well laid out in this book, which presents the background papers from the first planning session. The introduction is blunt in its warning that global warming "will feed on itself by destroying forests more rapidly than they can be generated. The result will be a rapid and progressive reduction in the capacity of the Earth to support life, including people." The book goes on to define "the extent to which forests are part of a stable and wholesome habitat for people", and it does so through a series of papers by such forest aficionados as George Woodwell, Kiliparti Ramakrishna, Richard Houghton, Darrell Posey, Herman Daly, Robert Repetto, Jagmohan Maini and Ola Ullsten. The result is a first-rate overview of the issues at stake, making it by far the best general appraisal available. The papers examine biology, ecology, ethnobotany, climate, economics, jurisprudence, government policies and, above all, the rationale for a commission. An excellent compendium of background analyses.

In the meantime, forests continue increasingly to be in demand for timber and agriculture. Much attention is directed to the decline of tropical rainforests, but a rainforest experiencing equally rapid depletion is the Tongass National Forest in the United States. Much of the damage arises from the same factor that lies behind overexploitation in Amazonia and Borneo: government subsidies. And consider the repercussions for Siberia's forests if China, with its growing consumer demand, enters the world's timber market. China's consumption of two principal wood products, sawn wood and panels, amounts to only 0.025 cubic metres per head per year. This is far below Indonesia's consumption, 0.065 cubic metres, and the average for the whole of Asia, 0.04 cubic metres (Japan, 0.306 cubic metres). Were China to increase its per-capita consumption to that of Indonesia, its total would amount to 59 per cent of Asia's total (and if it matched Japan's, 280 per cent of Asia's total).

Norman Myers is a visiting fellow of Green College, Oxford OX2 6NG, UK.

\section{New in paperback}

History of AIDS: Emergence and Origin of a Modern Pandemic by Mirko D. Grmek. The book explores the beginning of the epidemic as it appeared to contemporaries; scientific progress in attempts to understand the disease; the "remote past of hidden AIDS"; and biological and social causes. Princeton University Press, $\$ 16.95$, £13.50.

Theoretical Biology: Epigenetic and Evolutionary Order from Complex Systems edited by B. Goodwin and P. Saunders. Johns Hopkins University .Press, $\$ 18.50, £ 14$.

Four Neotropical Rainforests edited by Alwyn H. Gentry. Yale University Press, $\$ 37, £ 22.50$. See Nature 350, 32 (1990)
Methods and Problems in Greek Science: Selected Papers by G. E. R. Lloyd. Cambridge University Press, £16.95, $\$ 24.95$.

Volcanoes of North America edited by Charles A. Wood and Jürgen Kienle. Contains succinct descriptions by "leading experts" of 262 volcanoes and volcanic fields located in the continental United States, Alaska, Hawaii and Canada. Cambridge University Press, $£ 24.95, \$ 29.95$.

Cognitive Foundations of Natural History: Towards an Anthropology of Science by Scott Atran. Cambridge University Press, $£ 16.95, \$ 22.95$

Measuring Behaviour: An Introductory Guide by Paul Martin and Patrick Bateson (2nd edn). Cambridge University Press, $£ 9.95$, $\$ 16.95$.

\title{
Between input and output
}

\section{P. D. Wall}

The Merging of the Senses. By Barry E. Stein and M. Alex Meredith. MIT Press: 1993. Pp. 211. \$42.50, £38.25.

No sooner had Aristotle declared there to be five separate senses - sound, sight, smell, taste and touch - than he recognized that it would eventually be necessary to bring them back together again. In De Anima, he writes: "And indeed it is not possible that there should be some senseorgan special to the common sensibles, which we perceive incidentally with each sense".

There are at least three large categories of behaviour in which we bring together information gleaned from separate sensory channels. The first and most impressive is integrative. We automatically complement the hearing of difficult speech by adding the sight of lips, expression and gesture. Greeks still honour Aristotle by banging their wine glasses on the table to add sound to the other four senses of taste, feel, aroma and colour by which they appreciate their wine. To see an object allows us to identify it by feeling and vice versa. This book gives only a nod of appreciation to this category of integrative powers.

The second category is where alternative, often redundant, information from different inputs demands coordinated action. This aspect is wonderfully covered by the authors, important contributors to the subject. The main object of their study is orientation, for which visual, auditory or tactile cues are brought together to produce movement of eyes, ears, head and body towards the stimulus. With clear writing and excellent illustration, they combine anatomy, physiology and behaviour, focusing on the superior colliculus region of the brain, to explain how this feat is achieved. In doing so, they have to chart the convergence of the arriving information, the interaction of cortex and basal ganglia and the output motor systems. Three spatial maps of the origin of the stimulus are formed in register and merge to provide the motor system with clear information about the precise location of the stimulus. The task is a triumph of the brain. It is also a great compliment to neuroscientists that they can describe it so convincingly.

The third category is the correction of mismatch. The main example described relates again to orientation. Visual information about location is signalled via the retina but the eyes move with respect to the head, which moves with respect to the limbs. Eye movement promptly puts the visual map out of register with the auditory and body maps. How to solve this problem? The wise owl is a lethal missile whose beak aims at minor visual and auditory cues on the forest floor. It copes by locking its eyes in its skull, giving the bird its peculiar stare and keeping its auditory and visual maps in permanent register. For the rest of us, there are problems such as motion sickness produced by a mismatch of data on visual, vestibular and body senses, but we adjust. How? Suppression of incoherent data is one solution. Rapid plastic orientation of the maps to line them up with each other is another solution for which there is now some evidence. These questions bring us to the edge of present knowledge and to the end of this most readable and enjoyable book.

P. D. Wall is in the Division of Physiology, St Thomas's Hospital, Lambeth Palace Road, London SE1 7EH, UK. 